\title{
Effects of Early Unilateral Blur on the Macaque's Visual System. II. Anatomical Observations
}

\author{
Anita E. Hendrickson, ${ }^{1,2}$ J. Anthony Movshon, ${ }^{4}$ Howard M. Eggers, ${ }^{5}$ Martin S. Gizzi, ${ }^{4, a}$ Ronald G. Boothe, ${ }^{3, b}$ and \\ Lynne Kiorpes ${ }^{3,0}$ \\ Departments of 'Biological Structure, ${ }^{2}$ Ophthalmology, and ${ }^{3}$ Psychology, University of Washington, Seattle, Washington \\ 98195; 4Department of Psychology, New York University, New York, New York 10003; and 5 Harkness Eye institute, \\ College of Physicians and Surgeons, Columbia University, New York, New York 10036
}

We studied the effects of early unilateral blur on the anatomical organization of the visual pathways in 8 macaque monkeys. Blur was induced in one eye, beginning 2-14 d after birth, by $0.5 \%$ atropine twice a day. Atropinization was stopped at 6-8 months of age, and the animals were studied for anatomy 3-24 months later. The retina and all other eye tissues showed normal histology. In the dorsal lateral geniculate nucleus (LGN), cells in parvocellular layers receiving input from the atropine-treated eye were 9-32\% smaller and were more lightly stained than those in layers innervated by the untreated eye. These changes were generally larger in the LGN ipsilateral to the treated eye. LGN cell size changes were absent or much smaller in the magnocellular layers. In the striate cortex, the distribution of the oxidative enzyme cytochrome oxidase $(\mathrm{CO})$ was markedly altered in layer $4 \mathrm{C} \beta$. Layer $4 \mathrm{C} \beta$ is uniformly stained in normal animals, but showed a distinct pattern of alternating high and low $\mathrm{CO}$ bands in the atropine-treated animals; the bands of higher $\mathrm{CO}$ activity were narrower than the bands of lower activity and had a 857-1050 $\mu \mathrm{m}$ repeat. Fainter banding was seen in layers 4A, ${ }_{4} \mathrm{C} \alpha$, and 6 , but the density of the rows of dark CO-stained dots in layer 3 was unaffected. Double-labeling revealed that the narrow dark $\mathrm{CO}$ bands were associated with the centers of the ocular dominance columns devoted to the atropinetreated eye. The distribution of ${ }^{14} \mathrm{C}$-2-deoxyglucose uptake in visual cortex produced by $4.5-9 \mathrm{c} / \mathrm{deg}$ spatial frequency stimulation was strongly biased toward the untreated eye. The treated eye could, however, elicit reasonably strong uptake when stimulated with patterns containing lower spatial frequencies. These results suggest that unilateral neo-

\footnotetext{
Received Apr. 21, 1986; revised Dec. 5, 1986; accepted Dec. 5, 1986.

This research was supported by NIH Grants EY01208, EY04536, EY01730, EY02017, EY02536, RR00166, and HD02274. A.E.H. is the recipient of a Dolly Green Scholar Award frum Research to Prevent Blindness, Inc. J.A.M. held a Research Career Development Award from NIH (EY00187). M.S.G. was partly supported by a grant from the New York State Health Research Council. We are grateful for the critical suggestions of Dr. Helen Sherk, the excellent technical assistance of Bente Noble, Bradley Clifton, Ronald Jones, and Mark Hartley, and for the cooperation of United Airlines.

Correspondence should be addressed to Dr. J. A. Movshon, Department of Psychology, New York University, 6 Washington Place, New York, NY 10003.

a Present address: Department of Neurology, Mount Sinai Medical School, New York, NY 10036.

'Present address: Department of Psychology, Emory University, Atlanta, GA 30322.

c Present address: Department of Psychology, New York University, New York, NY 10003.

Copyright C 1987 Society for Neuroscience $0270-6474 / 87 / 051327-13 \$ 02.00 / 0$
}

natal blur preferentially affects the parvocellular layers of the LGN and layer $4 C \beta$ of striate cortex, which are the portions of the central visual system associated with the processing of information concerning fine spatial detail. These anatomical changes are consistent wlth the high spatlal frequency loss of vision demonstrated behaviorally and electrophysiologically in the atropine eye-driven visual system of these same animals.

Amblyopia is a loss of visual function that is not due to optical abnormalities or peripheral pathology. The visual losses seen in monocularly lid-sutured monkeys represent this condition in a particularly severe form. Among the most striking changes that occur in the primate visual system following early eyelid suture are anatomical alterations in the dorsal lateral geniculate nucleus (LGN) and striate cortex. Cell size and basophilic staining are markedly reduced in all LGN layers containing ganglion cell terminals from the retina of the deprived eye (von Noorden et al., 1970; von Noorden and Middleditch, 1975b; Hubel et al., 1977; Garey and Vital-Durand, 1981; Headon et al., 1985b). When the projections of LGN cells are studied, their axon distribution in striate cortex is seen to be contracted, while the axons from cells in LGN layers driven by the normal eye are expanded in a complementary fashion (Hubel et al., 1977; LeVay et al., 1980; Swindale et al., 1981). Bands of LGN input in striate layer $4 \mathrm{C}$ are the anatomical representation of the ocular dominance columns (Hubel and Wiesel, 1968), each of which is 350-500 $\mu \mathrm{m}$ wide in a normal monkey (Hubel and Wiesel, 1972; Hendrickson et al., 1978). In a lid-sutured monkey, the open eye expands its territory so that its axons occupy $60-90 \%$ of layer $4 \mathrm{C}$; closures within the first week after birth cause larger changes than closures at 8-10 weeks, near the end of the critical period (Hubel et al., 1977; LeVay et al., 1980; Swindale et al., 1981). This change in LGN synaptic input within layer $4 \mathrm{C}$ is accompanied by a loss of functional connections from the lidsutured eye throughout the visual cortex (Hubel et al., 1977; LeVay et al., 1980; Blakemore et al., 1981) and also by a profound behavioral loss of vision in this eye (von Noorden et al., 1970; von Noorden, 1973; Hendrickson et al., 1977; Harwerth et al., 1981).

In humans, amblyopia is often caused by early visual experience with a blurred retinal image in one eye due to refractive imbalance (anisometropia). This situation is not as drastic in its visual effects as lid suture in monkeys, although rare occurrences of total lid closure in human infants (von Noorden, 1973) 
Table 1. Summary of the rearing conditions and behavioral testing results from 8 monkeys ${ }^{a}$

\begin{tabular}{|c|c|c|c|c|c|c|c|c|}
\hline \multirow[b]{2}{*}{ Characteristic } & \multicolumn{8}{|c|}{ Monkey } \\
\hline & $\mathrm{LD}$ & $\mathrm{TC}$ & $\mathrm{DH}$ & NW & $\mathrm{GO}$ & GZ & $\mathrm{OH}$ & $\mathrm{OL}$ \\
\hline \multicolumn{9}{|l|}{ Rearing history } \\
\hline Eye treated & $\mathbf{R}$ & $\mathrm{L}$ & $\mathbf{R}$ & $\mathrm{L}$ & $\mathbf{L}$ & $\mathbf{R}$ & $\mathbf{R}$ & $\mathbf{R}$ \\
\hline Atropine begun (d) & 14 & 10 & 5 & 10 & 6 & 13 & 14 & 2 \\
\hline Atropine ended (mo.) & 7 & 8 & 10 & 8 & 6 & 7 & 6 & 6 \\
\hline Sacrificed (mo.) & 30 & 25 & 22 & 13 & 9 & 10 & 12 & 14 \\
\hline \multicolumn{9}{|l|}{ Final refraction } \\
\hline Untreated eye & +1.50 & +3.25 & 0 & +2.00 & - & +1.00 & - & +1.50 \\
\hline Treated eye & +2.75 & +3.25 & +6.00 & +5.00 & - & +2.50 & - & +3.50 \\
\hline \multicolumn{9}{|c|}{ Behavioral and evoked potential measurements, final acuity (cycles/deg) } \\
\hline Untreated eye & 34.9 & 31.5 & 36.9 & 29.6 & $57.5^{b . c}$ & 43 & $19.3^{b}$ & $22.8^{c}$ \\
\hline Treated eye & 29.3 & 28.1 & 3.7 & 6.7 & $18.7^{c}$ & 4.2 & $13.3^{b}$ & $5.3^{c}$ \\
\hline
\end{tabular}

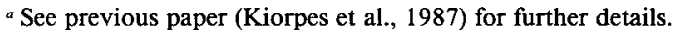

${ }^{b}$ High-frequency portion of function poorly defined.

c Evoked potential measurements only.

or prolonged therapeutic monocular patching (Awaya et al., 1973; Levi and Harwerth, 1980) show that the neonatal human visual system is at least as sensitive to monocular occlusion as that of the monkey. We wished to study a deprivation paradigm more akin to the unequal refractive error common in humans and so chose to treat one eye of neonatal monkeys with atropine. Atropinization produces a blurred retinal image by paralyzing the pupillary constrictor muscle to keep the pupil in the fully dilated state and the ciliary muscle to prevent lens accommodation for near vision. This produces a loss of image sharpness comparable in magnitude to that which leads to amblyopia in humans. In support of this assertion, we previously have shown that atropinization produces an amblyopia-like visual behavioral deficit in monkeys (Boothe et al., 1982; Kiorpes et al., 1987).

By applying modern neuroanatomical techniques to the visual system of these same animals, we hoped to ascertain whether there were selective changes in any of its subdivisions. This was motivated by the view that the macaque's visual system contains 2 major "functional streams" of visual information processing, which originate in 2 classes of retinal ganglion cells, $\mathrm{P} \alpha$ and $\mathrm{P} \beta$ (Hubel and Weisel, 1972; Schiller and Malpeli, 1978; Lund, 1980). P $\beta$ cells project to the parvocellular layers of the LGN, while $\mathrm{P} \alpha$ cells project to the magnocellular layers (Leventhal et al., 1981; Perry and Cowey, 1981; Perry et al., 1984). This segregation is preserved in the pathway from the LGN to the striate cortex. The axons of parvocellular neurons terminate in layer $4 \mathrm{~A}, 4 \mathrm{C} \beta, 6 \mathrm{~A}, 1$, and within the cytochrome oxidase $(\mathrm{CO})$ active dots of layer 3 , while magnocellular axons terminate in layer $4 \mathrm{C} \alpha$ and 6C (reviewed in Blasdel and Lund, 1983, and Hendrickson, 1985). Analysis of Golgi-impregnated axons and dendrites of these cortical neurons shows that the 2 streams remain relatively separate within striate cortex (Lund, 1980), while pathway labeling indicates that this is true even after visual signals leave the striate cortex for processing in extrastriate areas of the visual cortex (Livingstone and Hubel, 1984; Maunsell and Van Essen, 1983).

Functionally, the signals that pass through the parvocellular layers of the LGN (the "P" system) are believed to convey information about fine spatial detail and the chromatic content of the retinal image, while the signals passing through the magnocellular layer (the "M" system) emphasize information about lower contrast spatial features and the temporal content of the retinal image (Schiller and Malpeli, 1978; Kaplan and Shapley, 1982; Derrington and Lennie, 1984; but see differing views of Shapley and Perry, 1986). In the first paper of this series (Kiorpes et al., 1987), we showed that the visual behavioral defects in atropine-treated monkeys are primarily confined to high spatial frequencies. It is therefore natural to speculate that the effects of early blur might be more pronounced in the $P$ than the $M$ system. In this paper, we describe anatomical changes in the visual pathways of these same monkeys that suggest this to be the case. The final paper of this series (Movshon et al., 1987) shows that the effects of this rearing on the functional characteristics of visual cortical neurons are also consistent with a selective effect on visual mechanisms responsible for the relay of high spatial frequencies.

\section{Materials and Methods}

Subjects. The monkeys used in these experiments were the 8 macaques (Macaca nemestrina) whose rearing and treatment are described in the preceding paper (Kiorpes et al., 1987). The retinal image of one eye of each animal was blurred by twice-daily instillation of $0.5 \%$ atropine from 2-14 d after birth to at least 6 months of age. The vision of LD, TC, DH, GZ, NW, and $\mathrm{OH}$ was tested behaviorally. All showed reduced contrast sensitivity, especially at high spatial frequencies, when tested through the atropinized eye. The visual performance of GO and OL was evaluated using evoked potential methods, which revealed a similar performance deficit in the treated eye. Details of these measurements may be found in the preceding paper (Kiorpes et al., 1987); they are summarized, along with the rearing and refractive histories of the animals, in Table 1.

${ }^{14} \mathrm{C}$-2-deoxyglucose $(2 d G)$. This label was administered to study the localization of visual activity in the striate cortex of 6 monkeys. Four were stimulated during $2 \mathrm{dG}$ administration with visual patterns designed to reveal the relative effectiveness of visual inputs from the 2 eyes, and 2 were stimulated monocularly to reveal the effectiveness of inputs from a single eye.

Of the first 4 monkeys, LD, TC, and NW were studied at the conclusion of the single-unit recording experiments lasting $3 \mathrm{~d}$, as described in the following paper (Movshon et al., 1987); GO was studied in the same way but after evoked potential experiments lasting $12 \mathrm{hr}$. All of these animals were lightly anesthetized during $2 \mathrm{dG}$ administration with a combination of barbiturate and nitrous oxide and remained 
paralyzed throughout the visual presentation. The visual stimulus was arranged so that each nasal retina (temporal visual field) was stimulated by 1 of 2 identical CRT screens that subtended $12^{\circ}$ at the monkey's eye and had a mean luminance of $40 \mathrm{~cd} / \mathrm{m}^{2}$ (P31 phosphor). Sinusoidal grating targets were generated by the same PDP $11 / 34$ computer system used in the electrophysiological experiments described in the following paper (Movshon et al., 1987) and were always the same on both screens. Because only the nasal, contralaterally projecting portion of the retina of each eye was stimulated, each visual cortex was activated only by one eye, allowing a direct within-animal comparison of cortical $2 \mathrm{dG}$ uptake. Matching loci in each visual cortex thus contained $2 \mathrm{dG}$ uptake initiated by neural activity in either the treated or untreated eye.

To ensure that small errors of alignment did not produce binocular stimulation across the vertical meridian, we centered the CRT screens on the horizontal meridian and masked them so that a strip $4^{\circ}$ wide centered on the vertical meridian remained unstimulated. This configuration stimulated a roughly circular region of the visual field between $2^{\circ}$ and $14^{\circ}$ from the fovea, which is represented on the opercular and dorsal calcarine surface of striate cortex (Van Essen et al., 1984). The stimulus consisted of moving sinusoidal gratings of moderately high spatial frequency and contrast. In the absence of behavioral data on the visual resolution of macaques in the paracentral visual field, we assumed that resolution and contrast sensitivity fall with eccentricity approximately according to the relationships found by Robson and Graham (1981) for human observers. The spatial frequency ranges chosen were within 2 octaves of the presumed resolution limit for macaques in the stimulated portion of the visual field. The spatial frequencies used for LD were 6-9 cycles (c)/deg; for TC, NW, and GO they were $4.5-6 \mathrm{c} / \mathrm{deg}$; in all cases contrast was in excess of 0.7 . Six spatial frequencies within the selected range were presented for $10 \mathrm{sec}$ intervals in a pseudorandom sequence. Each new stimulus moved in a randomly chosen direction and was oriented orthogonal to that direction. The drift rate was randomly selected for each stimulus to be $1,2,4$, or $8 \mathrm{~Hz}$, which covers the range of optima for cortical neurons observed under identical stimulus conditions for single neurons in macaque striate cortex (Newsome et al., 1983). Over the $45 \mathrm{~min}$ of stimulation, 270 different stimuli were shown, covering the selected spatial frequencies and a full range of orientations, directions, and speeds of motion.

The other monkeys $\mathrm{OH}$ and $\mathrm{GZ}$ were stimulated monocularly during $2 \mathrm{dG}$ administration using a regimen designed to produce maximum label caused by all aspects of complex visual stimuli (Hendrickson and Wilson, 1979). The monkey was sedated with ketamine and restrained in a holding box; the lids of the treated (GZ) or untreated $(\mathrm{OH})$ eye were sutured shut, anesthetized with lidocaine ointment, and covered with black tape. The animal was allowed to become fully alert before the experiment was begun. During $2 \mathrm{dG}$ infusion the monkey viewed a brightly lit large board subtending $40^{\circ} \times 60^{\circ}$ that was covered with black-and-white and colored patterns containing all orientations and a wide range of spatial frequencies. The board was slowly moved back and forth horizontally during the stimulation period. In this arrangement, both cortices would contain labeling patterns caused only by the open eye.

Once the animal was positioned and the stimulus sequence begun, approximately $250 \mu \mathrm{Ci} / \mathrm{kg}$ of ${ }^{14} \mathrm{C}-2 \mathrm{dG}$ in $5 \mathrm{cc}$ of sterile saline was injected intravenously over $2 \mathrm{~min}$. The stimulus was continued for $45 \mathrm{~min}$; then the monkey was given a lethal intravenous dose of barbituate and immediately perfused intravascularly with 1 liter of $4 \%$ paraformaldehyde in $0.05 \mathrm{M}$ phosphate buffer, $\mathrm{pH}$ 7.6. The brain was quickly removed and the opercular striate cortex cut into blocks of known orientation, which were frozen in Freon chilled in liquid nitrogen.

$2 d G$ autoradiography and $C O$ staining. Electrophysiological recordings, when they were done, were confined to the regions of the cortex representing the central $2^{\circ}$ of the visual field, and this tissue was reserved for reconstructions of the electrode tracks. Blocks of the remaining striate cortex representing the visual field between $2^{\circ}$ and $14^{\circ}$ from the fovea were sectioned either perpendicular to the long axis of the ocular dominance columns or tangentially to the cortical surface. Frozen sections were cut serially at $25 \mu \mathrm{m}$ in a cryostat. Two serial sections were placed on a coverslip and rapidly dried on a $50^{\circ} \mathrm{C}$ hotplate. The third section in the series was stained for $\mathrm{CO}$ using a method slightly modified from Wong-Riley (1979). Coverslips were placed on posterboard in $\mathrm{X}$-ray cassettes and a sheet of Dupont mammography film laid over them, emulsion side facing the sections, in complete darkness. Films were exposed for 10-28 d and then developed in complete darkness in Kodak X-ray developer for $5 \mathrm{~min}$, fixed in Kodak Rapid Fix for $5 \mathrm{~min}$,

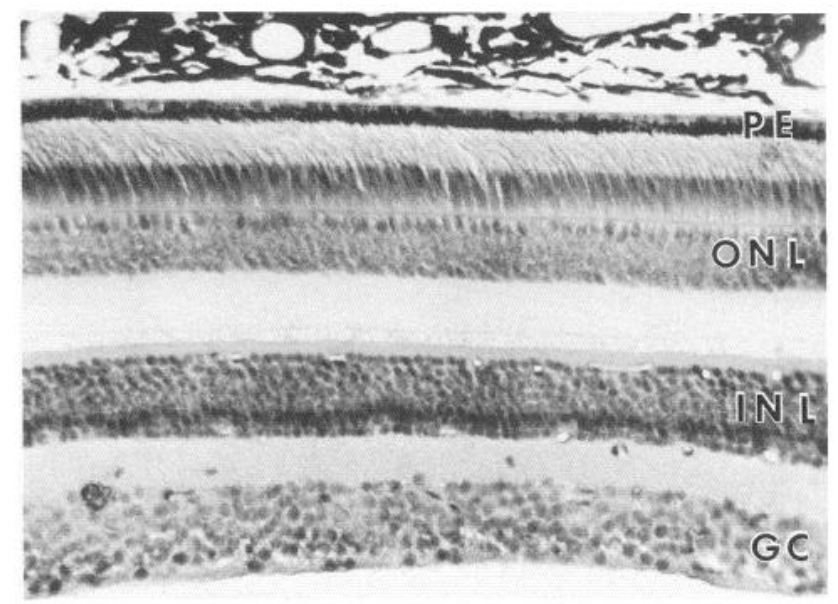

Figure 1. Photomicrograph of the central retina adjacent to the fovea from the atropinized eye of monkey TC. The retina is normal in lamination, thickness, and staining intensity. $P E$, pigment epithelium; $O N L$, outer nuclear layer; $I N L$, inner nuclear layer; $G C$, ganglion cell layer. $\times 240$.

and thoroughly washed. After acceptable films had been produced, selected sections were stained with cresyl violet to delineate cortical layers. In another series, serial sections were thaw-mounted on slides and freezedried for $12 \mathrm{hr}$ in the cryostat. These were exposed to film for $28 \mathrm{~d}$ at $8^{\circ} \mathrm{C}$ and then were stained for $\mathrm{CO}$ as described above.

In one monkey, NW, we purposely made a long, tangential electrode track and placed lesions to mark the location of the groups of units driven by the treated eye. The block containing this track was frozensectioned serially at $25 \mu \mathrm{m}$ and stained for CO.

Morphology and cell size measurements. The horizontal meridian of each eye, including the optic nerve and disk, fovea, and peripheral retina, was embedded in either paraffin or glycol methacrylate. Sections were cut serially at either $10 \mu \mathrm{m}$ for paraffin or $2 \mu \mathrm{m}$ for methacrylate. The thalamus was fixed for at least 1 week after perfusion, cryoprotected by sinking in $30 \%$ sucrose in phosphate buffer, and frozen-sectioned serially at $30 \mu \mathrm{m}$ through the LGN. A series of one section every $150 \mu \mathrm{m}$ through the LGN was stained using cresyl violet.

Cresyl violet-stained sections through the posterior LGN were chosen for drawing that corresponded to the same central region of the visual field studied with the $2 \mathrm{dG}$ and $\mathrm{CO}$ methods using the maps of Malpeli and Baker (1975). To assure that the same levels were compared in the 2 hemispheres, the posterior pole of the LGN was used as reference and 2-3 sections equidistant from this point on both sides were used for cell drawings. The cell outlines of 100 neurons from each LGN magnocellular layer ( 200 cells total) and 100 neurons from each parvocellular layer (400 cells total) lying near the representation of the horizontal meridian were drawn using a camera lucida and $800 \times$ magnification. Neurons were drawn that showed a clearly defined cytoplasmic border and a complete nucleus, often with a nucleolus. The cell areas were determined using a graphics tablet interfaced to a suitably programmed PDP 11/34 computer. Both LGNs of monkeys TC, LD, DH, NW, GZ, and OL were available for measurements, while only the LGN ipsilateral to the atropinized eye was available from monkeys $\mathrm{GO}$ and $\mathrm{OH}$.

\section{Results}

\section{Retina}

In 7 of the 8 monkeys, we examined the morphology of the retina at the light-microscopic level. The horizontal meridian, including the fovea and optic disk from all eyes, was studied using either paraffin sections of the whole eye or plastic sections of selected areas of the eye. There was no morphological difference between the atropine-treated and untreated eyes in any of the animals. The retina showed normal differentiation of all cell layers (Fig. 1), and the fovea was of normal depth with 

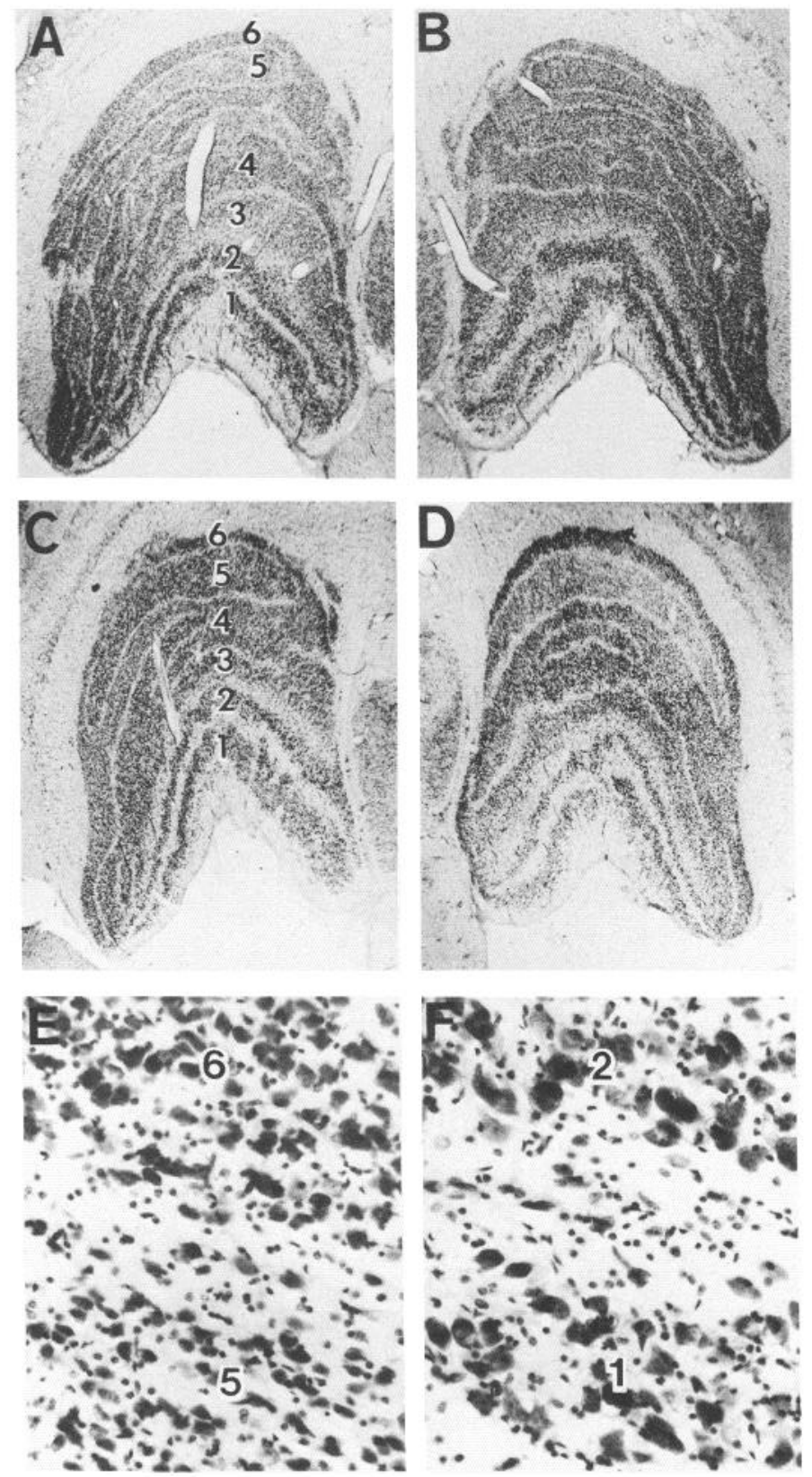

Figure 2. Low-power photomicrographs of the dorsal lateral geniculate nuclei (LGN) from monkey DH $(A, B)$ and NW $(C, D) . A$ and $D$ are from the LGN ipsilateral to the atropinized eye. Note that the ipsilateral parvocellular layers 3 and 5, which receive input from the atropinized eye, are paler staining that the contralateral layers 4 and 6 receiving input from the untreated eye. The staining density of the parvocellular layers 4 and 6 receiving contralateral axons from the atropinized eye $(B, C)$ and all magnocellular layers are less obviously affected. $\times 12 . E$ and $F$. Higher-power view of the parvocellular $(E)$ and magnocellular $(F)$ layers from the LGN of DH, ipsilateral to the atropinized eye. There is a pronounced difference in staining intensity and size between untreated-input layer 6 and atropinized-input layer 5 , but atropinizedinput layer 2 appears quite normal. $\times 140$.

typical thin, elongated cones. The pigment epithelium, iris, and ciliary body were well pigmented, while the cornea was of normal thickness and cellular organization.

\section{Cell size changes in the $L G N$}

In the light microscope at low power it was possible to distinguish between the staining intensity of parvocellular layers re- ceiving axons from the treated and untreated eye, especially on the side ipsilateral to the atropine-treated eye (Fig. 2,A-D). At higher power it could be seen that the neurons in the parvocellular layers innervated by the atropinized eye were both smaller and markedly reduced in basophilic staining (Fig. 2E). There was little obvious difference between magnocellular layers in either size or staining in most animals (Fig. $2 F$ ).

We measured neuronal cell size in both LGNs of 6 animals (LD, TC, DH, NW, GZ, and OL) and in the LGN ipsilateral to the atropinized eye of $\mathrm{GO}$ and $\mathrm{OH}$. All sections used for measurement were from the portion of the nucleus representing the central $15^{\circ}$ of the visual field (Malpeli and Baker, 1975) and were matched to be from the same LGN level for right and left sides of the same animal. Figure 3 shows these data in histogram form; the open bars represent data from the atropine-treated monkeys and the filled bars data from 2 normally reared animals. Each bar represents the percentage difference in mean cell area between cells in adjacent magnocellular or parvocellular laminae. For comparison, mean cell areas of ipsilateral parvocellular layers 3 and 5 were averaged, as were data from contralateral parvocellular layers 4 and 6 . Mean cell areas were directly compared for magnocellular ipsilateral layer 2 and contralateral layer 1 . The upward direction represents instances in which cells in untreated eye layers (U) are larger than cells in atropine-treated eye (A) layers.

In the 2 normally-reared 1-year-old monkeys (Hendrickson et al., 1975), average cell size does not differ by more than $4 \%$ between contra- and ipsilaterally innervated parvocellular layers, in agreement with other data on normal macaque LGN (von Noorden and Middleditch, 1975a; Headon et al., 1981). In the LGN ipsilateral to the atropinized eye, in all atropine-treated monkeys there is a consistent difference between parvocellular layers (Fig. 3, upper right), with the treated-eye neurons being $11-31 \%$ smaller than untreated-eye neurons. In the LGN contralateral to the treated eye (Fig. 3, upper left) in TC and OL the size difference between parvocellular layers is in the same range as in the normal monkeys. In LD and NW, there is a larger difference, but the ipsilaterally innervated layers still are more affected than the contralateral layers. In DH and GZ the difference is large and about equal on the 2 sides.

The cell-size changes in the magnocellular layers are less consistent (Fig. 3, lower half). In normal monkeys we find that ipsilaterally innervated layer 2 can be up to $7 \%$ larger than contralaterally innervated layer 1 (also see von Noorden and Middleditch, 1975a; Headon et al., 1981). Thus, in the contralateral LGN of our experimental monkeys, cells in layer 2 that are innervated by the treated eye should be slightly larger than cells in layer 1; this is true for monkeys OL, TC, LD, GZ, and NW (Fig. 3). In DH, however, cells in the untreated layer 2 were $23 \%$ larger. In magnocellular layers ipsilateral to the atropine eye, although layer 2 is supplied by the treated eye, the cells were slightly larger than those of layer 1 in TC, GZ, and DH, suggesting a normal size relationship. Layer 2 cells were $14 \%$ larger in LD, while in NW, layer 2 cells were $13 \%$ smaller. This method of comparison indicates that, with the possible exception of $\mathrm{DH}, \mathrm{LD}$, and $\mathrm{NW}$, cell size in the parvocellular layers was consistently affected by blur, while cell size in the magnocellular layers was not.

Another means of comparison is to pair the same layers from both nuclei, for instance, to compare cell sizes in layer 6 that would receive crossed nasal ganglion cell axons from the atropine-treated eye in one hemisphere and from the untreated eye 

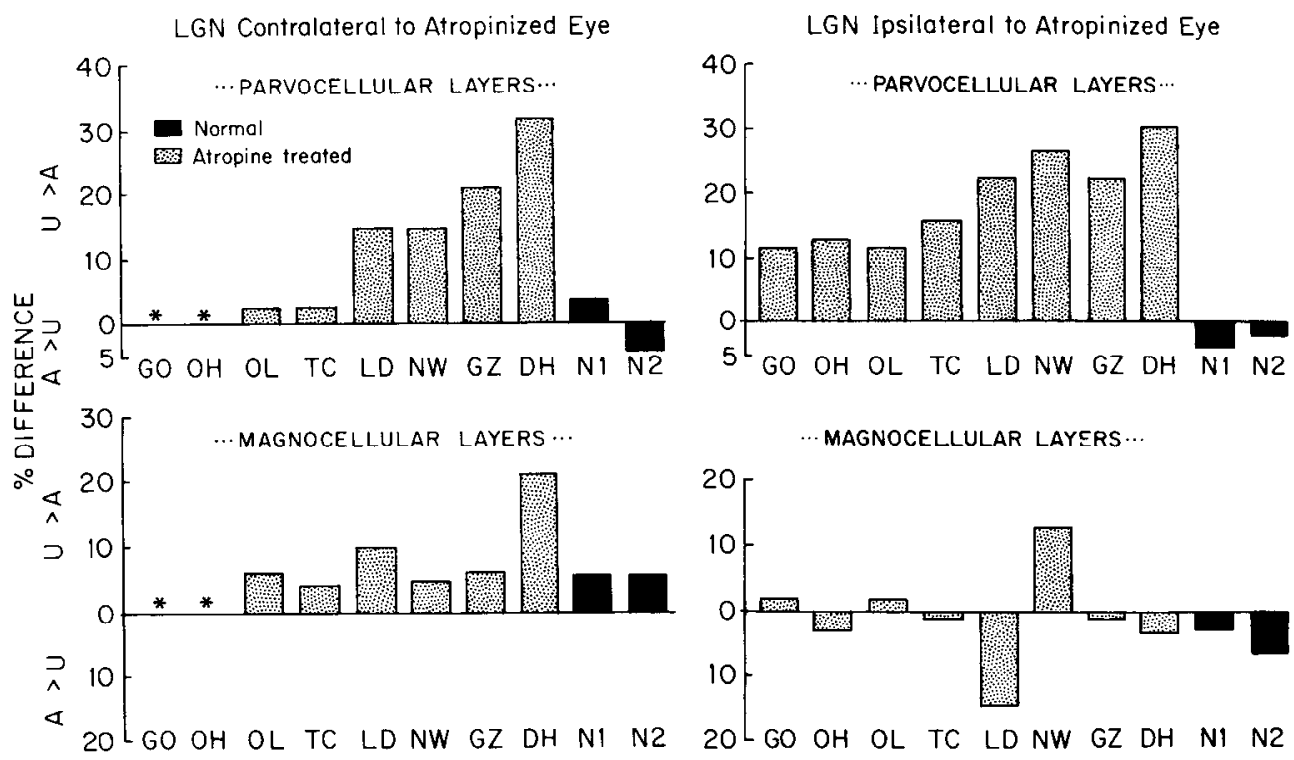

Figure 3. Graphic representation of ccll-sizc changes in LGN following carly postnatal atropine treatment of 1 eye. The percentage difference in mean cell area is shown for all animals. For comparison the mean cell areas of contralateral parvocellular layers 4 and 6 and ipsilateral parvocellular layers 3 and 5 were averaged. The percentage difference for the parvocellular layers from the atropine-treated animals (stippled bars) is shown for the LGN contralateral (upper left) or ipsilateral (upper right) to the atropine-treated eye. The percentage difference from the atropine-treated monkeys (stippled bars) in magnocellular mean cell area between contralateral layer 1 and ipsilateral layer 2 is shown for the LGN contralateral (lower left) and ipsilateral (lower right) to the atropine-treated eye. The percentage differences between the same layers in normal monkeys are shown in black bars. Upward deflections indicate that cells in layers receiving axons from the atropine-treated $(A)$ eye are smaller than cells receiving input from the untreated $(U)$ eye; downward deflections are the reverse. All animals showed a marked difference between parvocellular layers on the ipsilateral side, and most showed a similar but smaller difference on the contralateral side. The magnocellular layers showed no consistent direction of change.

in the other. This approach eliminates the cell-size bias in the magnocellular layers, which complicates the intrageniculate comparison of Figure 3. The results of this method applied to monkeys TC, NW, LD, GZ, DH, and OL are presented in Table 2. These data are in overall agreement with the intrageniculate comparison, in that in most animals both ipsilateral and contralateral parvocellular layers show a statistically significant size difference with the treated eye layers always having the smaller cells. The contralateral side of TC had size changes of borderline significance, in agreement with the intrageniculate comparison. OL had a small but significant difference only on the contralateral side, in contrast to all of the other monkeys. On the other hand, this method of comparison provides more clear evidence that the magnocellular layers are less affected than the parvocellular layers by the atropine rearing. In ipsilateral layer 2 , only DH showed a highly significant $12 \%$ difference, while TC, GZ, and NW showed a less significant $5-7 \%$ size change; in these monkeys the layer 2 cells receiving axons from the atropinetreated eye were the smaller. For contralateral layer 1 , only NW showed a significant change, again with the atropine-treated layer cells being $11 \%$ smaller.

\section{Striate cortex}

$C O$ staining. When sections of striate cortex from a normal $M$. nemestrina monkey are reacted for the oxidative enzyme $\mathrm{CO}$, clear laminar differences are apparent (Blasdel and Lund, 1983; Horton, 1984; Hendrickson, 1985). Figure $4 A$ shows a normal monkey striate cortex section from the opercular cortex, stained for $\mathrm{CO}$. The plane of section passes perpendicularly across the ocular dominance columns (LeVay et al., 1985). Layers 4A and $4 \mathrm{C}$ are darkly reactive, while $4 \mathrm{~B}$ is lightly stained. The staining in layer $4 \mathrm{C}$ is uniform, and darkest in the cortex. Above and below layer 4 , regular periodic regions of $\mathrm{CO}$ staining are evi- dent, which are especially prominent in layers $2 / 3$. These dots of enhanced $\mathrm{CO}$ activity (also called patches, blobs or puffs by other workers) are aligned in parallel rows when the cortex is viewed en face. Experiments using double labeling (Hendrickson et al., 1981; Horton and Hubel, 1981; Horton, 1984) have shown that each row of dots marks the center of an ocular dominance column from one eye, with adjacent rows alternating between the 2 eyes.

In all of the atropine-treated monkeys, $\mathrm{CO}$ staining of striate cortex showed a marked change. In perpendicular sections (Fig. $4, B, C)$, layer $4 \mathrm{C} \alpha$ was uniformly stained, similar to results in normal monkeys, but layer $4 \mathrm{C} \beta$ was subdivided into alternating narrower, darkly stained bands and wider, more lightly stained bands. Sometimes the dark $\mathrm{CO}$ bands can be traced through to the upper cortical laycrs, where they intersect with a layer 3 dot (Fig. $4 B$, starred arrows), indicating that these $\mathrm{CO}$ bands lie along the center of an ocular dominance column. The spacing of layer 3 dots (arrowheads) was approximately twice that of the $4 \mathrm{C} \beta$ bands (arrows), suggesting that each band marks every other eye. Paired serial sections stained for cresyl violet did not show changes in the basophilic staining of layer $4 C$ (Fig. $4 D$ ), even when $\mathrm{CO}$ bands were clearly present (Fig. $4 E$ ). In langential sections through opercular cortex, the rows of $\mathrm{CO}$ dots in layer $2 / 3$ (Fig. $4 F$ ) were unchanged in staining density or spacing. In $\mathrm{LD}$ the repeat averaged $457 \mu \mathrm{m}$; in $\mathrm{DH}, 429 \mu \mathrm{m}$; and in $\mathrm{GZ}$, $525 \mu \mathrm{m}$, compared to a repeat of 471 and $505 \mu \mathrm{m}$ in 2 normal $M$. nemestrina monkeys. Alternating bands first appear in layer $4 \mathrm{~A}$, where they can be seen to connect to every other row of dots in layer 3 (Fig. $4 G$, arrowheads). Layer $4 \mathrm{C} \alpha$ was more darkly stained overall, but narrow, darker bands could also be faintly seen in this layer as well (Fig. $4 H$ ). The most obvious change has occurred in $4 \mathrm{C} \beta$ (Fig. $4, H, I$ ), which was more lightly stained than normal and contained narrow, irregularly beaded bands of 


\begin{tabular}{|c|c|c|c|c|}
\hline Subject & Atropinized & Untreated & $\begin{array}{l}\mathrm{A} / \mathrm{u} \\
\text { Percentage } \\
\text { difference }\end{array}$ & $p$ value \\
\hline \multicolumn{5}{|c|}{ Parvocellular, ipsilateral layers $3+5$} \\
\hline $\mathrm{TC}$ & $109 \pm 18$ & $124 \pm 30$ & -12 & $<0.005 \dagger$ \\
\hline NW & $144 \pm 14$ & $158 \pm 24$ & -11 & $<0.005 \dagger$ \\
\hline LD & $93 \pm 20$ & $121 \pm 22$ & -23 & $<0.005 \dagger$ \\
\hline $\mathrm{GZ}$ & $165 \pm 26$ & $241 \pm 32$ & -31 & $<0.005 \dagger$ \\
\hline $\mathrm{DH}$ & $95 \pm 12$ & $144 \pm 17$ & -35 & $<0.005 \dagger$ \\
\hline $\mathrm{OL}$ & $161 \pm 41$ & $164 \pm 33$ & +2 & $<0.6$ \\
\hline \multicolumn{5}{|c|}{ Parvocellular, contralateral layers $4+6$} \\
\hline $\mathrm{TC}$ & $121 \pm 18$ & $126 \pm 16$ & -4 & $<0.05>0.02 *$ \\
\hline NW & $137 \pm 14$ & $191 \pm 16$ & -29 & $<0.005 \dagger$ \\
\hline $\mathrm{I}, \mathrm{D}$ & $103+26$ & $121 \pm 24$ & -14 & $<0.005 \dagger$ \\
\hline GZ & $190 \pm 37$ & $213 \pm 40$ & -11 & $<0.005 \dagger$ \\
\hline $\mathrm{DH}$ & $98 \pm 13$ & $137 \pm 17$ & -29 & $<0.005 \dagger$ \\
\hline $\mathrm{OL}$ & $165 \pm 32$ & $177 \pm 37$ & +7 & $<0.02>0.01^{*}$ \\
\hline \multicolumn{5}{|c|}{ Magnocellular, ipsilateral layer 2} \\
\hline $\mathrm{TC}$ & $279 \pm 42$ & $294 \pm 46$ & -5 & $<0.02>0.01^{*}$ \\
\hline NW & $255 \pm 35$ & $275 \pm 59$ & -7 & $<0.01^{*}$ \\
\hline $\mathrm{LD}$ & $308 \pm 80$ & $312 \pm 87$ & -1 & $<0.5$ \\
\hline $\mathrm{GZ}$ & $342 \pm 68$ & $368 \pm 68$ & -7 & $<0.01^{*}$ \\
\hline $\mathrm{DH}$ & $293 \pm 66$ & $333 \pm 60$ & -12 & $<0.005 \dagger$ \\
\hline OL & $280 \pm 67$ & $289 \pm 71$ & -3 & $<0.3$ \\
\hline \multicolumn{5}{|c|}{ Magnocellular, contralateral layer 1} \\
\hline $\mathrm{TC}$ & $281 \pm 58$ & $275 \pm 40$ & +2 & $<0.5$ \\
\hline NW & $261 \pm 55$ & $292 \pm 36$ & -11 & $<0.005 \dagger$ \\
\hline LD & $291 \pm 81$ & $279 \pm 76$ & +4 & $<0.3$ \\
\hline $\mathrm{GZ}$ & $333 \pm 70$ & $333 \pm 71$ & 0 & - \\
\hline $\mathrm{DH}$ & $282 \pm 57$ & $288 \pm 69$ & -2 & $=0.5$ \\
\hline OL & $270 \pm 86$ & $288 \pm 74$ & -6 & $<0.2$ \\
\hline
\end{tabular}

This method of data presentation allows a direct comparison of cell sizes in the same layer that is subject to atropine-treated eye input in one LGN and untreated eye input in the other LGN. Ipsilateral parvocellular cell sizes are an average of layers 3 plus 5 (200 cells each) and contralateral parvocellular cell sizes are an average of layers 4 plus 6 (200 cells each). Contralateral mangocellular is layer 1 and ipsilateral is layer $2(100$ cells each). Size differences were tested by a 2 -tailed Student's $t$ test, and then further corrected by the Bonferroni method for multiple comparisons (Johnson and Wichen, 1982). *, Significance by Student's $t$ $\dagger$ significance at or beyond that set by the Bonferroni correction. These are called borderline and highly significant respectively in the text.

darker CO staining. These narrow dark bands had a spacing of $1050 \mu \mathrm{m}$ in $\mathrm{LD}, 857 \mu \mathrm{m}$ in $\mathrm{DH}$, and $900 \mu \mathrm{m}$ in $\mathrm{GZ}$, which is similar to the center-to-center spacing for ocular dominance columns from 1 eye of normal macaques (Hubel et al., 1977; Hendrickson ct al., 1978) and about twice that of the layer 3 dots in the same animal. This spacing again indicates that one eye is involved in these changes; the assignment of the darker $\mathrm{CO}$ bands to treated or untreated eye ocular dominance columns formed the basis of double-label experiments (see below). Similar darker $\mathrm{CO}$ bands are present in layer 6 (Fig. $4 E$, arrowheads), but both the background and the band staining are much lighter in layer 6 than in layer 4 .

${ }^{14} \mathrm{C}-2 d G$ labeling. We used this technique to compare the pattern and magnitude of cortical activity that could be elicited through the atropine-treated and untreated eye. Using the dual screen technique (Materials and Methods), the cortex contralateral to each eye is stimulated solely by that eye, allowing an intra-animal comparison of cortical activity. Usable $2 \mathrm{dG}$ results were obtained in TC, LD, and GO, with a marked asymmetry in labeling intensity and pattern between the cortical hemispheres stimulated by the untreated and treated eyes. For some unknown reason, neither side of NW showed any clear pattern.

In $\mathrm{TC}$ (Fig. $5, A-C$ ), the cortex driven by the untreated eye nasal retina had distinct banded patterns in layers $4 \mathrm{~A}$ and $4 \mathrm{C}$, with lighter banding in layer 6 after a stimulus of $4.5-6 \mathrm{c} / \mathrm{deg}$. The $2 \mathrm{dG}$ dot patterns in layers $2 / 3$ were indistinct, which may have been due to the stimulus containing relatively high spatial frequencies and no chromatic modulation (Tootell and Silverman, 1981). In the cortex stimulated by the atropinized eye nasal retina (Fig. 5,D-F) there was only a hint of banding in layer 4 and very little patterned activity in any other layers.

In monkey GO, a similar stimulus of 4.5-6 c/deg produced good $2 \mathrm{dG}$ activity in layer 4 of both sides, which indicated a change in pattern between atropine-eye and untreated-cyc driven cortex. Narrow, regular, parallel stripes of activity separated by wider bands of unlabeled cortex occurred on the side driven by the atropinized eye (Fig. $6 A$ ). In the cortex stimulated by the untreated eye (Fig. $6 B$ ), the converse pattern was found of wide, parallel 2dG-labeled bands separated by narrower unlabeled bands. The treated bands were $70-100 \%$ wider than the untreated. The ocular dominance bands in one section from each side have been inked in to illustrate the width differences. The level of activity outside of layer 4 was much lower than in $4 \mathrm{C}$ itself, but bands or columns could be seen outside of 4 as well as within it.

Monkey LD showed an intermediate level of response to a 6-9 c/deg stimulus. Some faint activity was seen in layer 4 of the atropine eye-driven cortex (Fig. $6 \mathrm{C}$ ), but the labeling was much lower than that in the untreated eye-driven cortex (Fig. $6 D$ ), in which crisply labcled columns extended throughout the cortex. Figure $6 D$ shows that the highest labeling in layer 4 is in layers $4 \mathrm{C} \beta$ and $4 \mathrm{~A}$. This is also the case in the atropine-eye driven cortex, but is not apparent in Figure $6 C$. Both cortices show widely spaced bands of higher activity in the underlying prestriate cortex.

Identity of the $\mathrm{CO}$ bands. In order to identify the source of the $\mathrm{CO}$ bands, monkey $\mathrm{GZ}$ was stimulated entirely through the untreated eye, using stimuli containing both chromatic and achromatic contrast. The monkey was alert and could move both its head and eyes; under these conditions we have found heavy $2 \mathrm{dG}$ labeling in both layer 4 and the $\mathrm{CO}$ dot system in layers 2/3 (Hendrickson and Wilson, 1979). Serial sections were prepared for sequential $2 \mathrm{dG}$ and $\mathrm{CO}$ staining. In both cortices (Fig. $7, A-D$ ), there was prominent $2 \mathrm{dG}$ labeling of columns in layers $4 \mathrm{~A}$ and $4 \mathrm{C}$ and of alternate rows of layer 3 dots, corresponding to the labeled columns in layer 4 . The $2 \mathrm{dG}$-labeled bands in layer $4 \mathrm{C}$ were wide and separated by narrow unlabeled bands. In the same sections stained for $\mathrm{CO}$, the narrow, darkly stained $\mathrm{CO}$ bands match the narrow unlabeled $2 \mathrm{dG}$ bands, indicating that these narrow bands do indeed represent the ocular dominance columns driven by the atropinized eye. Alternately processed serial sections of monkey LD also showed the same correspondence in the cortex stimulated by the untreated eye (Fig. $7, E-H)$. A similar experiment involving the stimulation of $\mathrm{OH}$ 's atropinized eye did show good $2 \mathrm{dG}$ labeling of the cortex, indicating that the atropinized eye could effectively stimulate the striate cortex when visual stimuli not restricted to high spatial frequencies were used. However, this monkey did not have clear 


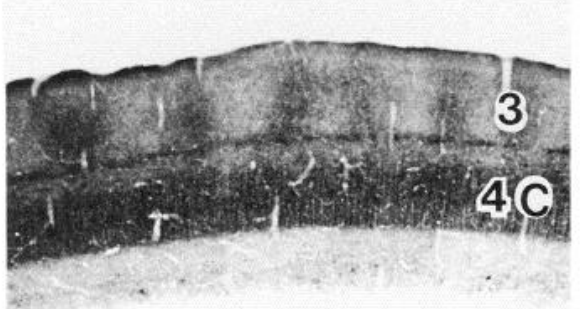

A

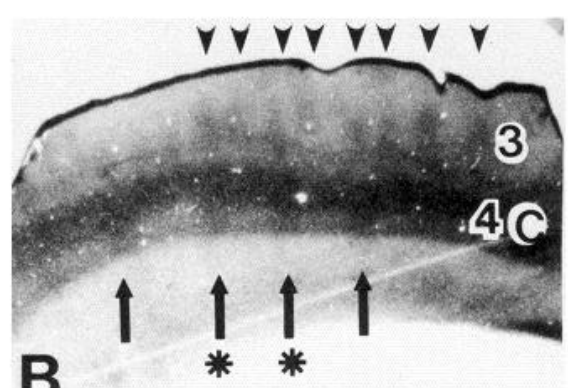

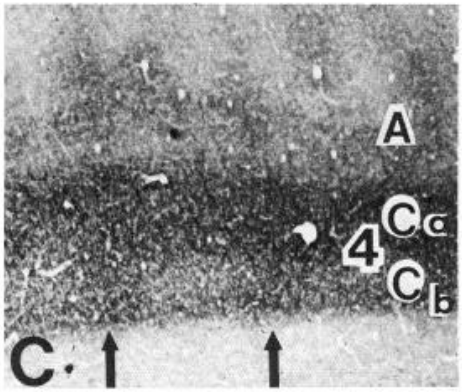
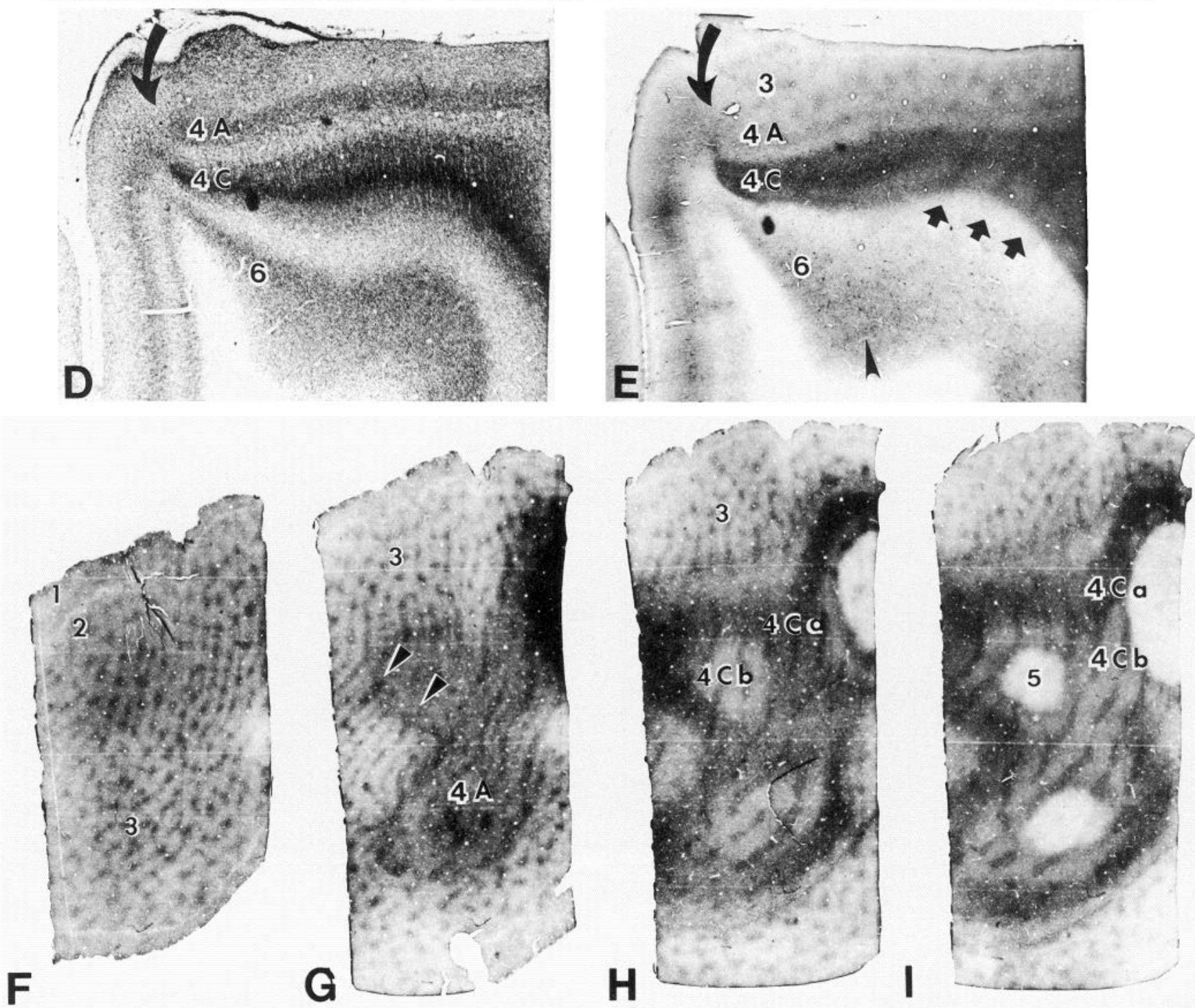

Figure 4. Comparison between normal $(A)$ and atropinized $(B, C)$ monkey striate cortex stained for cytochrome oxidase (CO). In normal monkey, layer $4 C$ is uniformly dense, but the atropine monkey LD has bands $(B$, arrows) in layer $4 C \beta$; the bands clearly in register with a cytochrome dot in layer 3 are starred. The spacing of the cytochrome oxidase dots in the atropine-treated monkey $(B)$ is marked by arrowheads; these were determined from this and adjacent serial sections. $\times 20$. Panel $C$ is an enlargement of the portion of layer 4 in $B$ marked by the starred arrows to show the difference in density between $4 \mathrm{C} \alpha$ and $4 \mathrm{C} \beta . \times 90 . D$ and $E$, Comparison of cresyl violet $(D)$ and $C O(E)$ staining in serial sections from the right cortex of monkey GO. The striate-prestriate border is indicated by the large arrow. The upper half of layer 4C is more uniformly and heavily stained for $\mathrm{CO}$ than the lower half, while the reverse is true for cresyl violet. Perpendicular, regularly spaced, narrow, darker-staining bands (small arrows) can be seen in $4 \mathrm{C} \beta$ after $\mathrm{CO}$ but not cresyl violet staining. Fainter bands occur in layer $6(C$, arrowheads $) . \times 30 . F-I$, $\mathrm{CO}$-stained serial sections passing sequentially through deeper layers of the left striate cortex of monkey LD. The pattern of rows of dots in upper cortical layers is quite normal $(F, G)$, but in layer 4A narrow, darkly staining bands appear that merge into alternating rows of dots (arrows, $G$ ). These bands are faintly seen in $4 \mathrm{C} \alpha$ but stand out clearly against the pale background of $4 \mathrm{C} \beta(H, I) . \times 30$. 

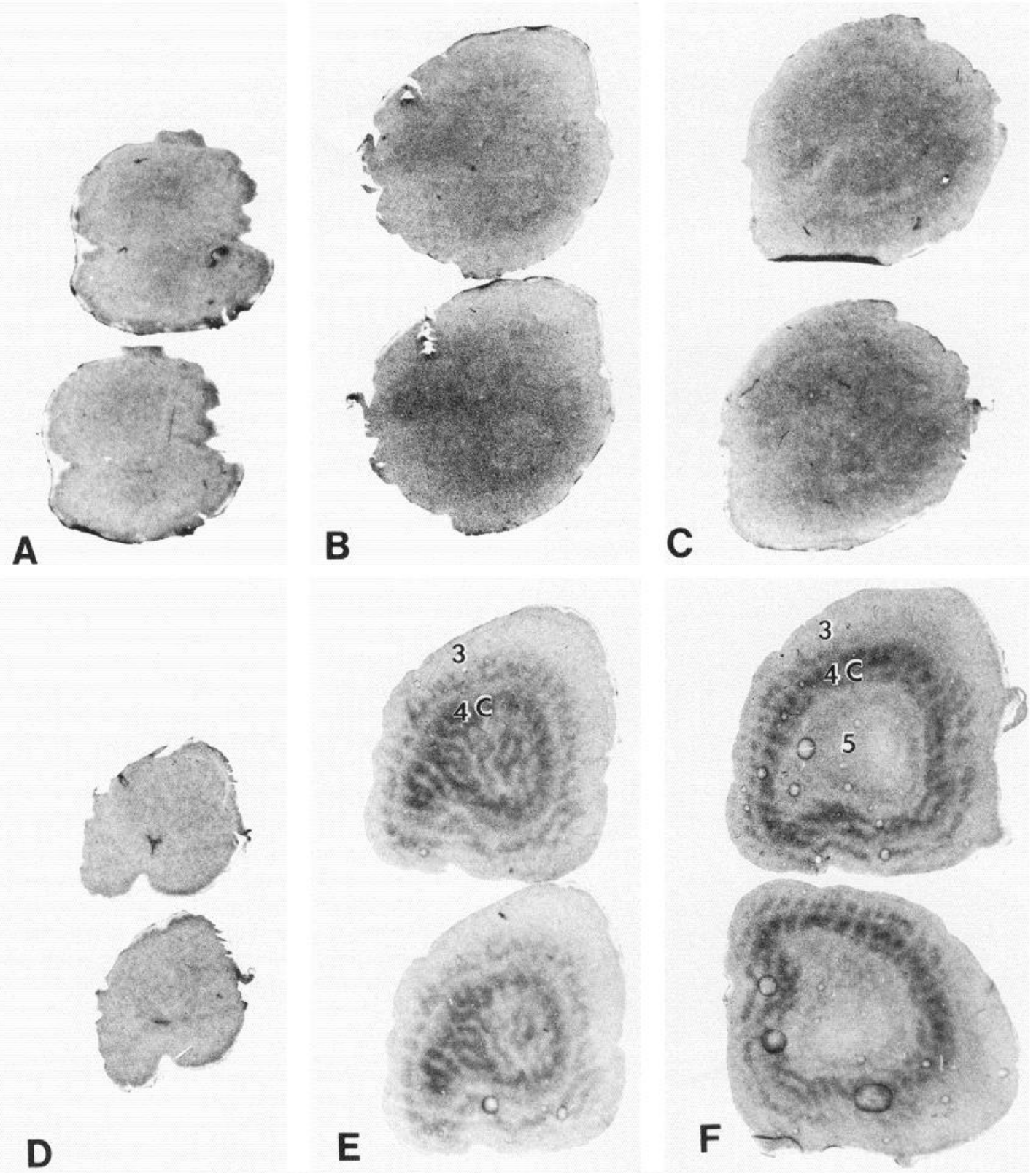

Figure 5. Tangential sections of the opercular striate cortex from monkey TC that have been autoradiographed for ${ }^{14} \mathrm{C}-2-$ deoxyglucose (2dG) localization. $A-C$ are from the cortex stimulated by the atropinized nasal retina; $D-F$, from the cortex stimulated by the untreated nasal retina. The $4.5-6 \mathrm{c} / \mathrm{deg}$ stimulus produced relatively little uptake in cortical layers $2 / 3$ on either side $(A, D)$. Layers $4 \mathrm{~A}$ and $4 \mathrm{C}$ showed striking, heavy columnar uptake in the hemisphere driven by the untreated eye $(E, F)$ but not the atropinized eye $(B, C) . \times 3$.

enough $\mathrm{CO}$ bands in $4 \mathrm{C}$ to permit us to match them to the $2 \mathrm{dG}$ patterns.

We also sought to identify the eye of origin of the inputs to the CO-rich bands by intentionally marking cortical regions driven by the atropine eye during an electrophysiological recording experiment of the type described in detail in the following paper (Movshon et al., 1987). In monkey NW, we directed a long tangential penetration across the ocular dominance columns in a direction parallel to the lip of the lunate sulcus and placed 5 electrolytic lesions near distinct, well-separated clusters of units dominated by the atropine-treated eye. The reconstruction of this electrode track from CO-stained sections is shown in Figure 8. Each lesion is related to an ocular dominance column marked by a dark band in layer $4 \mathrm{C} \beta$, providing independent confirmation that these columns were driven by signals from the atropine-treated eye.

\section{Discussion}

\section{Retina}

There is now abundant evidence that monocular visual deprivation influences both the anatomical and functional connectivity of central visual pathways, while the retina of the deprived eye remains relatively normal. Following monocular eyelid suture or lens/goggle rearing in cats, there is no change in the electrophysiological characteristics of retinal ganglion cells when recordings are done within the eye (Cleland et al., 1980; Thibos and Levick, 1982) or optic nerve (Sherman and Stone, 1973). Similar electrophysiological studies have not been done in mon- 

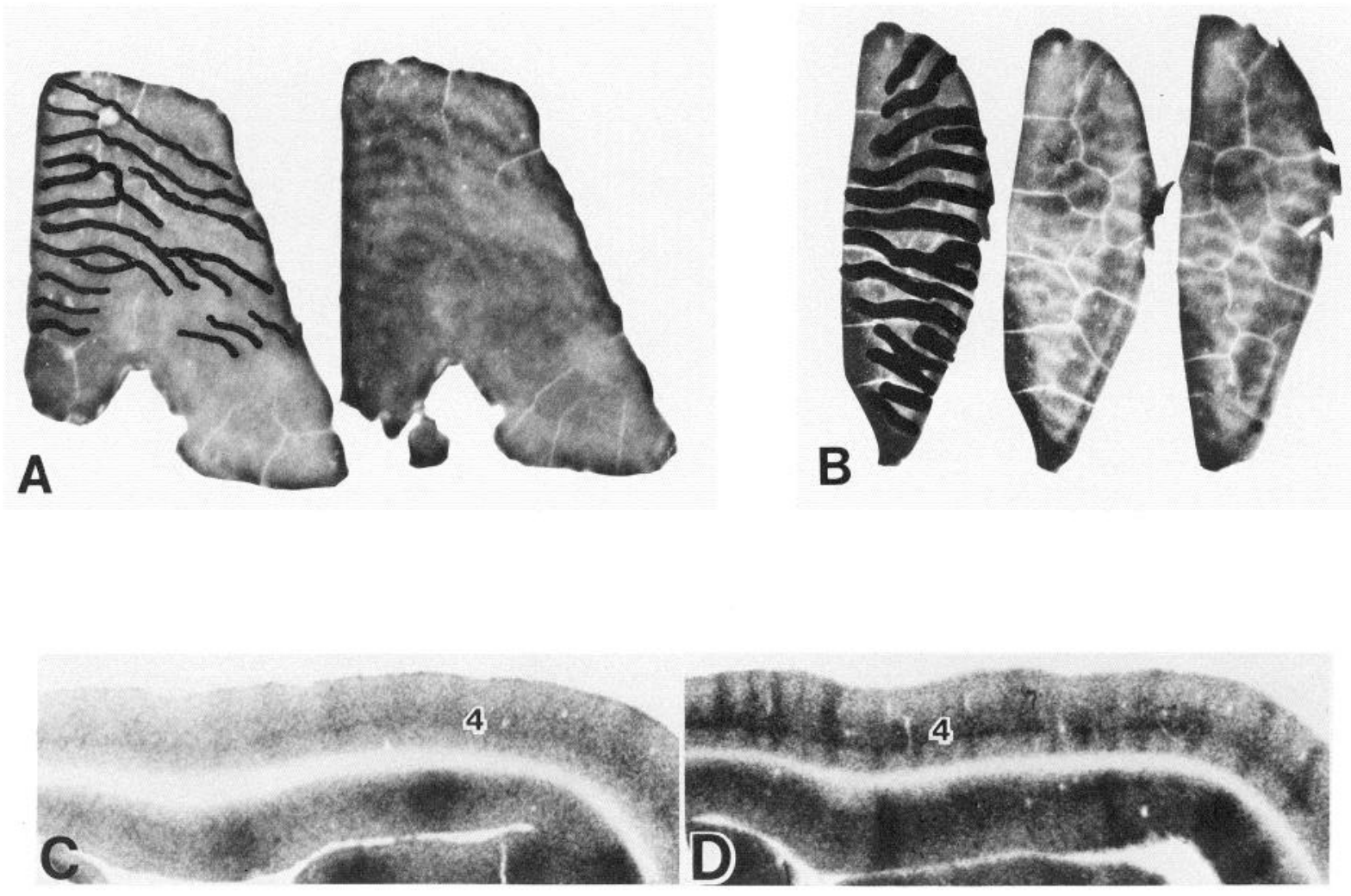

Figure 6. $A$ and $B$, En face sections mainly through layer $4 \mathrm{C}$ of monkey GO processed for $2 \mathrm{dG}$. In $A$ the cortex was driven by the atropinized eye; in $B$ by the untreated eye. The labeled ocular dominance columns have been inked-in on 1 section to emphasize the difference in patterns. The atropinized eye columns are narrow, while the untreated eye columns are much wider. $\times 3 . C$ and $D$, Vertical sections through the opercular striate cortex of monkey LD to compare labeling in the atropinized-eye-driven cortex $(C)$ and untreated-eye-driven cortex $(D)$. The labeling is minimal in the atropinized-eye-driven cortex, with faint columns extending above and below the slightly more intense layer 4C. In contrast, the untreated-eye-driven cortex has heavy labeling in layer $4 \mathrm{C}$ and clear periodic columnar activity in layers above and below $4 \mathrm{C}$. The underlying prestriate cortex has localized thick bands on both sides. $\times 12$.

keys, but ERG recordings from both unilateral and bilateral closure eyes are reported to be normal (von Noorden et al., 1970). We found no anatomical alterations in our monkeys' retina, iris, ciliary body, or cornea following monocular atropine, consistent with other reports of normal morphology in lid-sutured and aphakic monkey eyes (von Noorden and Crawford, 1977). We did not measure the cell sizes of retinal ganglion cells, but no obvious change in size or number could be detected when the 2 retinae were compared. The only deprivation-induced anatomical change that has been reported in monkey retina occurred in one animal surviving for more than 2 years after monocular lid suture; the size of retinal ganglion cell nuclei was reduced $14 \%$ in the sutured eye (von Noorden et al., 1977).

\section{Lateral geniculate nucleus}

Even low-power microscopy showed a marked change in the staining characteristics of the LGN, especially on the side ipsilateral to the atropinized eye. The parvocellular layers receiving input from the atropine-treated eye are more lightly stained, and cell measurements showed that they contain smaller cells than the adjacent layers receiving input from the untreated eye. When opposite eye layers are compared in the same LGN ipsilateral to the atropine-treated eye, cells in all monkeys were between 11 and $31 \%$ smaller in the parvocellular layers receiving axons from the treated eye. On the contralateral side, 4 of 6 monkeys had smaller but similar parvocellular changes. The magnocellular layers did not show an obvious effect in most animals; the 3 animals with a large magnocellular change (NW, $\mathrm{LD}$, and $\mathrm{DH}$ ) had large changes in parvocellular layers as well. When the same LGN layers from both hemispheres are compared, all animals except OL and TC showed a highly significant change in the parvocellular layers of both sides, with the atropine-treated input layers consistently having smaller cells. This comparison showed more clearly that cell size changes in the magnocellular layers were much smaller, were mainly ipsilateral, and were clearly present in fewer animals. It appears, therefore, that neonatal blur preferentially affects the size of parvocellular neurons, with cells ipsilateral to the treated eye being at greater risk.

The largest of these LGN cell-size changes are similar in magnitude to those reported for a variety of rearing paradigms. These include Old World monkeys with a postnatal eyelid suture and long survival time (Hendrickson et al., 1975; von Noorden and Middleditch, 1975b; Vital-Durand et al., 1978; Headon et al., 1979, 1985b; LeVay et al., 1980); Old World monkeys with surgically induced strabismus (von Noorden and Middleditch 1975b); or Old World monkeys following neonatal lens removal (von Noorden and Crawford, 1977). Lid suture in the neonatal prosimian Galago (Casagrande and Joseph, 1980) and form deprivation in a newborn human (von Noorden et al., 1983) also produce LGN cell-size changes of similar magnitude. These papers show that magnocellular and parvocellular layers appear 

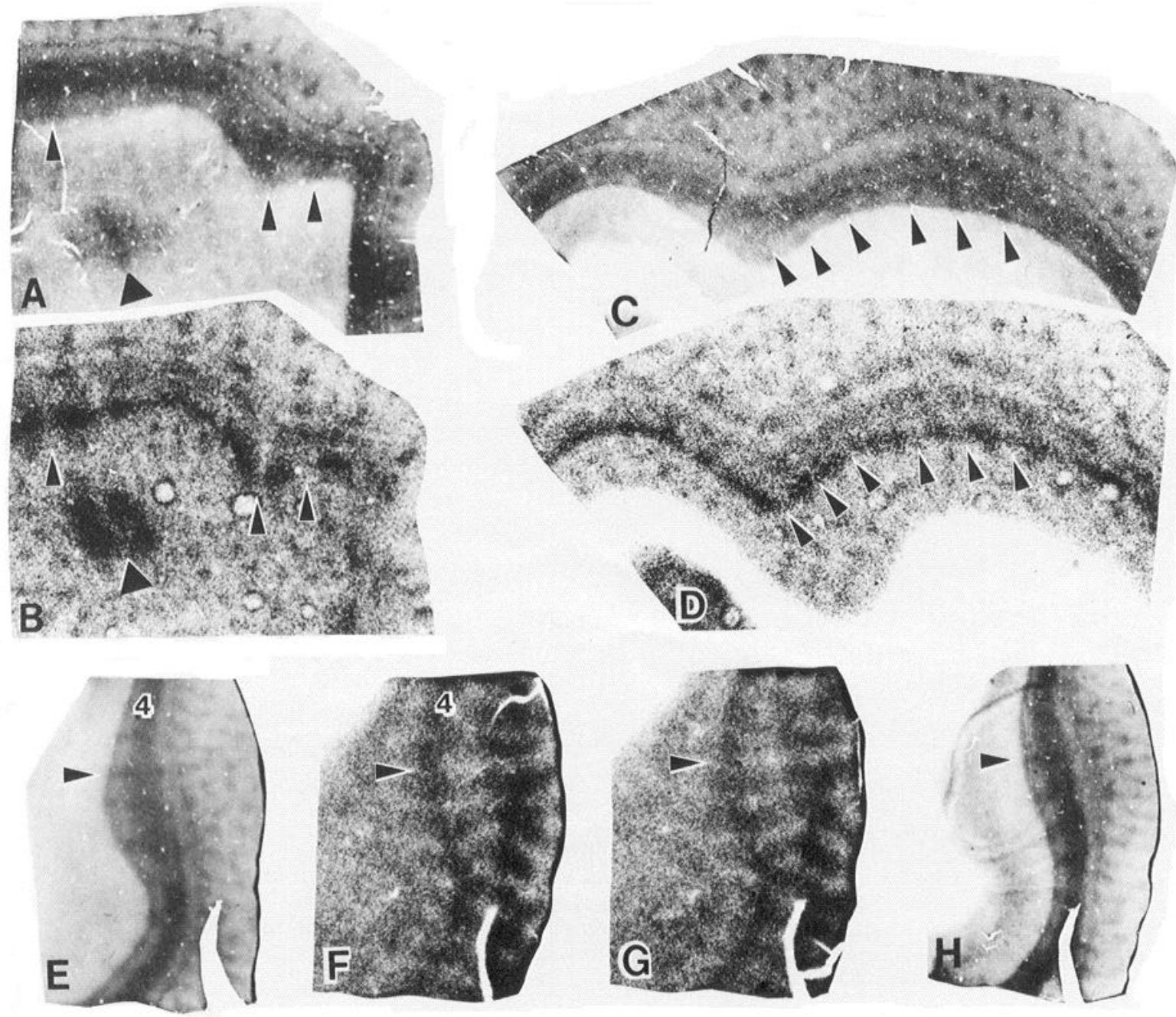

Figure 7. Freeze-dried tangential sections from monkey GZ processed for $\mathrm{CO}(A, C)$ after autoradiography $(B, D)$. The normal eye was stimulated by broad-frequency, nonoriented colored patterns. The narrow dark bands in $4 \mathrm{C} \beta$ revealed by $\mathrm{CO}$ staining $(A, C)$ are marked by arrowheads. These bands correspond to the unlabeled narrow gaps in $4 C \beta$ of the deoxyglucose sections $(B, D)$, which also are marked by small arrowheads. In the lower left portion of $A$ and $B$, a glancing section through $4 \mathrm{C} \beta$ shows a single narrow $\mathrm{CO}$ band ( $A$, large arrowhead) and 2 wide, heavily labeled deoxyglucose bands separated by a narrow unlabeled band $(B$, large arrowhead), which corresponds to the $C O$ band. $\times 30$. $E-H$, Serial sections cut perpendicularly through the right opercular cortex of $\mathrm{LD}$, showing the alignment of narrow $\mathrm{CO}$ bands in $4 \mathrm{C} \beta(E, H)$ with unlabeled narrow bands representing the atropine-treated eye in the deoxyglucose sections $(F, G)$. One sequence is marked by arrowheads. $\times 30$.

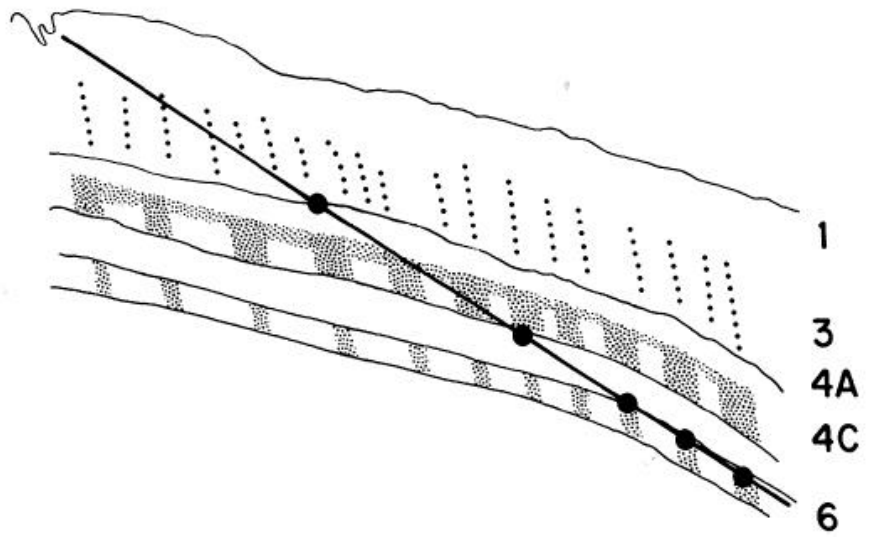

Figure 8. Reconstruction of the electrode track through the foveal striate cortex of monkey NW, as seen in $\mathrm{CO}$ serial sections. The 5 marking lesions were made at sites driven by the atropinized eye. All lesions are adjacent to a CO-dense band or its extension in layers $4 \mathrm{~A}$, $4 \mathrm{C} \beta$, or 6 (stipple). to be differentially affected by different types of deprivation. Neonatal eyelid suture and aphakia cause a cell-size change in both layers, while eyelid suture of late onset, esotropic and exotropic strabismus, and atropinization (this study) show a preferential effect on the parvocellular layers. The different LGN results for form deprivation (aphakia vs atropinization) may only be a difference in degree rather than kind, for when the atropine-induced amblyopia was behaviorally profound, as in $\mathrm{DH}, \mathrm{NW}$, and GZ, a change in magnocellular neurons also occurred. This preferential parvocellular cell-size response to moderate blur suggests that form deprivation differentially affects the "P system" located predominantly within the parvocellular layers of LGN and layer $4 \mathrm{C} \beta$ of striate cortex (Hubel and Wiesel, 1972; Hendrickson et al., 1978; Perry and Cowey, 1981; Blasdel and Lund, 1983). In a single human case of anisometropic amblyopia of unknown etiology there also was a much larger cell-size change in the parvocellular layers (von Noorden et al., 1983), suggesting that the same would be true of the human visual system. 
Our animals also showed a much larger change on the side ipsilateral to the atropinized eye, which may be related to an asymmetry in macaque cone and retinal ganglion cell number. Perry et al. (1984) and Perry and Cowey (1986) report that the peripheral nasal retina has up to 3 times as many ganglion cells as the peripheral temporal retina, which gives rise to the ipsilateral LGN projections. The central retina has a smaller but similar asymmetry. This imbalance is carried into the cortex where in the more peripheral retinal representation the ocular dominance columns from the temporal retina are broken into patches and clearly occupy less than $50 \%$ of the cortical space (LeVay et al., 1985). Work in our laboratory (Packer et al., 1986) indicates that central temporal retina in $M$. nemestrina also contains fewer cones than nasal retina at the same eccentricity. Given this numerical imbalance, the temporal retinal pathways might be more handicapped when placed in a competitive situation against nasal input.

Although there is a consistent direction in the size difference between parvocellular LGN neurons in treated and untreated eye input layers (untreated $>$ treated), we are not able to state the absolute direction of this size change compared to normal monkeys. Headon et al. (1979, 1981, 1985b) have directly compared normal LGN cell size in one set of monkeys to deprivedeye and open-eye LGN cell size in a second set. These authors assert that the balance of cell change takes place in the untreated eye layers as a hypertrophy and that the deprived eye layers usually do not shrink, as has been supposed by others. A similar comparison in our animals was not possible because both our normal and atropinized animals varied markedly between individuals in the absolute size of LGN ncurons, pcrhaps duc to our use of frozen sections.

It has been suggested that neurons are most sensitive to deprivation during a rapid growth phase (Hickey, 1977). In the human LGN, parvocellular neurons have reached $95 \%$ of their adult size by 6 months after birth, while the magnocellular layers increase in size until 24 months of age (Hickey, 1977). The monkey shows a similar growth pattern, in which the parvocellular layers are virtually adult by birth, but the magnocellular layers still grow somewhat after birth (Headon et al., 1985a). Because postnatal atropine treatment affects mainly the parvocellular layers, and this can occur even when treatment is not begun until the end of the second week after birth, it would appear that rapid growth is not a prerequisite for these formdeprivation effects to occur.

What is the cause of the changes in LGN cell size? Eyelid suture causes a reduction in the cortical area occupied by thalamic axons driven by the deprived eye (Hubel et al., 1977; LeVay et al., 1980; Blakemore et al., 1981; Swindale et al., 1981) and smaller LGN cell size and reduced basophilia are the probable result of this reduced arbor. Alternatively, hypertrophy of the untreated eye neurons to support an enlarged axon arbor (Headon et al., 1979, 1981, 1985b) might also be the result of expanded columns. We do not have direct ocular dominance column measurements for all of our monkeys, but GO, GZ, NW, and DH all showed reductions in the amount of cortex driven by the treated eye, as measured by anatomical or physiological means. This reduction in cortical area is believed to be largely due to active and unequal postnatal competition between the axons of the 2 eyes within layer 4 of striate cortex during ocular dominance column formation (Guillery, 1972; Hubel et al., 1977; Blakemore et al., 1981). Interestingly, New World monkeys lack ocular dominance columns in cortex and should not be subject to this competition, yet they also show marked LGN cell size changes after eyelid suture (Lin and Kaas, 1980; Tigges et al., 1984). In other situations where the possibility for cortical competition is removed, for instance, within the region of LGN representing the monocular segment (von Noorden and Middleditch, 1975b) or by creating an artificial monocular segment (Hendrickson et al., 1975), LGN neurons still show cell-size changes. These findings suggest that at least 2 mechanisms are operative in the primate, binocular competition within cortex and some direct "deprivation" effect, perhaps at the retinogeniculate synapse itself. Both processes would inhibit the growth of cell bodies in the treated eye layers and/ or enhance those in the untreated eye layers.

Despite the changcs in ccll sizc, clcctron-microscopic examination of the LGN synaptic organization of deprived monkeys (Wilson and Hendrickson, 1981) has not shown any qualitative or quantitative changes. Similarly, single-unit recordings in deprived LGN show that spatial resolution develops at a normal rate and reaches normal levels in the $L G N$ layers receiving input from the deprived eye (Blakemore and Vital-Durand, 1979; Movshon et al., 1987). This constellation of results lends support to the idea that the major functional effects of visual deprivation occur within the striate cortex.

\section{Striate cortex}

The $2 \mathrm{dG}$ results in $\mathrm{TC}$ and $\mathrm{LC}$ revealed reduced cortical responsiveness to midrange spatial frequency stimulation in the treated-eye-driven cortex but not in the untreated-eye-driven cortex. This is consistent with the results of striate cortex electrophysiological recording (Movshon et al., 1987), in which these animals had markedly reduced responsiveness to these and higher spatial frequencies in cortical units driven by the treated eye. On the other hand, $2 \mathrm{dG}$ labeling for a midrange stimulus was partly retained in GO. In this animal an altered ocular dominance pattern was found in layer 4 , with the untreated eye elicting wider columns than the treated eye. GO was not studied electrophysiologically or behaviorally but did have a performance deficit in the atropine-treated eye as measured by evoked cortical potentials. Whether this difference was functionally more or less severe than the deficit in TC and LD cannot be directly compared, but if it were less, it could explain the difference in responsiveness. The difference in responsiveness of the atropine-eye-driven cortex of TC and LD and of GO also could have been influenced by the shorter time of anesthesia experienced by GO (10 vs $48 \mathrm{hr}$ or more for TC and LD).

The changes in $\mathrm{CO}$ staining in the atropine-eye-driven striate cortex were consistent with a marked change in the parvocellular pathway and a lesser effect in the magnocellular pathway. The primary target of axons from the parvocellular layers is layer $4 \mathrm{C} \beta$, with smaller inputs to layers $6 \mathrm{~A}, 4 \mathrm{~A}, 3$, and 1 (Blasdel and Lund, 1983; Hendrickson, 1985). The most obvious change in $\mathrm{CO}$ staining pattern was in layers $4 \mathrm{~A}$ and $4 \mathrm{C} \beta$, although layer 6 usually showed an enhancement of $\mathrm{CO}$ activity within the same columns that showed increases in layer 4. Most monkeys had uniform dark staining in $4 C \alpha$, the site of magnocellular input which is consistent with the minimal LGN cell size changes found in these layers. The rows of $\mathrm{CO}$ dots, which are aligned along the centers of the ocular dominance columns, also did not show changes in staining intensity. This dot system has been reported to contain a large number of poorly oriented, colorspecific units that often are monocular (Livingstone and Hubel, 1984). Postnatal defocus due to atropinization should markedly 
degrade spatial resolution but should have little effect on the processing of chromatic information, so the lack of an atropine effect on the dots is consistent with this proposed parcellation of cell function within layer 3 .

Our finding that the heavier $\mathrm{CO}$ staining in layer $4 \mathrm{C} \beta$ resides in ocular dominance columns associated with the atropinized eye is not easily explained. Enucleation (Horton and Hubel, 1981; Horton, 1984), abolition of ganglion cell activity (WongRiley and Carroll, 1984), or lid suture of an adult monkey (Hendry and Jones, 1986) rapidly produces a marked decrease in CO staining within columns driven by the affected eye. There are no reports from neonatal deprivation paradigms showing marked CO staining changes in primate cortex. Given the small number of cortical neurons driven by a neonatally sutured eye (Blakemore et al., 1981), the decrease in size and number of synaptic terminals within the sutured eye's patches of layer 4 (cat striate cortex; Tieman, 1984) and the marked reduction in the basophilia and size of LGN neurons receiving input from the sutured eye, one might predict a marked decrease in $\mathrm{CO}$ staining of monocularly deprived striate cortex. What might explain the apparent decrease in $\mathrm{CO}$ activity within the untreated-eye-driven columns of layer $4 C \beta$ ? As reported in the following paper (Movshon et al., 1987), we found that, in contrast to results for neonatal eyelid suture, many neurons were responsive in all layers of cortex to the atropine-treated eye. These units were typical for all perimeters except for thcir inability to respond to high spatial frequencies. However, some shift in ocular dominance column size in favor of the untreated eye also has occurred. This suggests that LGN synapses driven by the treated eye should have been formed in cortex in a relatively normal manner during development but within a smaller overall area of $4 \mathrm{C} \beta$. The resulting increased synaptic density might result in relatively normal metabolic staining. Conversely, the untreated eye columns would expand in size but decrease in $\mathrm{CO}$ staining intensity, presumably due to an overall decrease in synaptic density. Increased CO staining is seen in some normal animals along the column centers in layers 4 and 6 (Horton, 1984; Hendrickson, 1985), so this change in our atropine-treated monkeys could be an exaggeration of a normal but poorly understood aspect of cortical organization. Alternatively, this altered pattern of $\mathrm{CO}$ staining could reflect a redistribution of some intrinsic cortical systcm acting within the atropine-driven areas of cortex. $\mathrm{CO}$ staining is not confined to excitatory input regions but is found in all types of synaptic terminals, as well as axons, cell bodies, and dendrites within cortex (Wong-Riley, 1979; Carroll and Wong-Riley, 1984). Interestingly, LeVay et al. (1980) reported a similar change in axon neurofilament staining patterns using the silver-based Liesengang method. They found that brief eyelid suture resulted in enhanced staining of the narrowed sutured-eye columns and reduction of staining in the wider openeye columns. Their monkey had "near-normal" acuity, suggesting a functional but deprived eye system somewhat like our atropine monkeys.

In these atropine-treated monkeys, the anatomical changes that occurred within the visual system were qualitatively consistent across animals and were seen most clearly within the LGN and striate cortical pathways associated with the parvocellular pathways. The amount of LGN cell-size change and $2 \mathrm{dG}$ labeling intensity was also correlated with the severity of the behavioral loss in contrast sensitivity and spatial resolution in the same animals that we reported in the previous paper (Kiorpes et al., 1987). In the final paper in this series (Movshon et al., 1987), we show in striate cortex that the physiological effects of neonatal monocular atropine treatment also are consistent with a functional change predominantly affecting the parvocellular system, and that the magnitude of anatomical and behavioral change in a given monkey is predictive of the degree of functional loss within that animal's striate cortex.

\section{References}

Awaya, S., Y. Miyake, Y. Imaizumi, Y. Sinose, T. Kanda, and K. Komuro (1973) Amblyopia in man suggestive of stimulus deprivation amblyopia. J. Ophthalmol. 17: 69-82.

Blakemore, C., and F. Vital-Durand (1979) Development of the neural basis of visual acuity in monkeys. Speculation on the origin of deprivation amblyopia. Trans. Ophthalmol. Soc. UK 99: 363-368.

Blakemore, C., F. Vital-Durand, and L. Garey (1981) Recovery from monocular deprivation in the monkey. I. Reversal of physiological effects in the visual cortex. Proc. R. Soc. London [Biol.] 211: 399423.

Blasdel, G. G., and J. S. Lund (1983) Termination of afferent axons in macaque striate cortex. J. Neurosci. 3: 1389-1413.

Boothe, R. G., L. Kiorpes, and A. Hendrickson (1982) Anisometropic amblyopia in Macaca nemestrina monkeys produced by atropinization of one eye during development. Invest. Ophthalmol. Vis. Sci. 22: 228-233.

Carroll, E. W., and M. T. T. Wong-Riley (1984) Quantitative light and electron microscopic analysis of cytochrome oxidase-rich zones in the striate cortex of the squirrel monkey. J. Comp. Neurol. 222: $1-17$.

Casagrande, V. A., and R. Joseph (1980) Morphological effects of monocular deprivation and recovery on the dorsal lateral geniculate nucleus in Galago. J. Comp. Neurol. 194: 413-426.

Cleland, B. G., D. E. Mitchell, S. Gillard-Crewther, and D. P. Crewther (1980) Visual resolution of retinal ganglion cells in monocularlydeprived cats. Brain Res. 192: 261-266.

Derrington, A. M., and P. Lennie (1984) Spatial and temporal contrast sensitivity of neurones in lateral geniculate nucleus of macaque. $\mathbf{J}$. Physiol. (Lond.) 357: 219-240.

Garey, L. J., and F. Vital-Durand (1981) Recovery from monocular deprivation in the monkey. II. Reversal of morphological effects in the lateral geniculate nucleus. Proc. R. Soc. London [Biol.] 213: 425433.

Guillery, R. W. (1972) Binocular competition in the control of geniculate cell growth. J. Comp. Neurol. 144: 117-130.

Harwerth, R. S., M. L. J. Crawford, E. L. Smith, and R. L. Boltz (1981) Behavioral studies of stimulus deprivation amblyopia in monkeys. Vision Res. 21: 779-789.

Headon, M. P., J. J. Sloper, R. W. Hiorns, and T. P. S. Powell (1979) Cell size changes in undeprived laminae of monkey lateral geniculate nucleus after monocular closure. Nature 281: 572-574.

Headon, M. P., J. J. Sloper, R. W. Hiorns, and T. P. S. Powell (1981) Cell sizes in the lateral geniculate nucleus of normal infant and adult rhesus monkeys. Brain Res. 229: 183-186.

Headon, M. P., J. J. Sloper, R. W. Hiorns, and T. P. S. Powell (1985a) Sizes of neurons in the primate lateral geniculate nucleus during normal development. Dev. Brain Res. 18: 51-56.

Headon, M. P., J. J. Sloper, R. W. Hiorns, and T. P. S. Powell (1985b) Effects of monocular closure at different ages on deprived and undeprived cells in the primate lateral geniculate nucleus. Dev. Brain Res. 18: 57-78.

Hendrickson, A. E. (1985) Dots, stripes and columns in monkey visual cortex. Trends Neurosci. 8: 406-410.

Hendrickson, A., and J. R. Wilson (1979) A difference in ${ }^{14} \mathrm{C}$-deoxyglucose patterns in striate cortex between Macaca and Saimiri monkeys following monocular stimulation. Brain Res. 170: 353-358.

Hendrickson, A., J. Lund, and R. Kalina (1975) The interaction of retinal lesions and eyelid closure in the monkey dorsal lateral geniculate. Soc. Neurosci. Abstr. 1: 478.

Hendrickson, A., J. Bowles, and E. B. McLean (1977) Visual acuity and behavior of monocularly deprived monkeys after retinal lesions. Invest. Ophthalmol. Vis. Sci. 16: 469-473.

Hendrickson, A. E., J. R. Wilson, and M. P. Ogren (1978) The neuroanatomical organization of pathways between the dorsal lateral geniculate nucleus and visual cortex in Old World and New World primates. J. Comp. Neurol. 182: 123-136. 
Hendrickson, A. E., S. P. Hunt, and J.-Y. Wu (1981) Immunocytochemical localization of glutamic acid decarboxylase in monkey striate cortex. Nature 292: 605-607.

Hendry, S. H. C., and E. G. Jones (1986) Reduction in number of immunostained GABAergic neurons in deprived-eye dominance columns of monkey area 17. Nature 320:750-752.

Hickey, T. (1977) Postnatal development of the human lateral geniculate nucleus: Relationship to a critical period for the visual system. Science 198: 836-838.

Horton, J. (1984) Cytochrome oxidase patches: a new cytoarchitectonic feature of monkey visual cortex. Phil. Trans. Roy. Soc. Lond. 304: 199-253.

Horton, J., and D. H. Hubel (1981) Regular patchy distribution of cytochrome oxidase staining in primary visual cortex of macaque monkey. Nature 292: 762-764.

Hubel, D. H., and T. N. Wiesel (1968) Receptive fields and functional architecture of monkey striate cortex. J. Physiol. (Lond.) 195: 215243

Hubel, D. H., and T. N. Wiesel (1972) Laminar and columnar distribution of geniculo-cortical fibers in the macaque monkey. J. Comp. Neurol. 46: 421-450.

Hubel, D. H., T. N. Wiesel, and S. LeVay (1977) Plasticity of ocular dominance columns in monkey striate cortex. Phil. Trans. R. Soc. Lond. B 278: 377-409.

Johnson, R. A., and D. W. Wichen (1982) Applied Multivariate Statistical Analysis, p. 197, Prentice-Hall, Englewood Cliffs, NJ.

Kaplan, E., and R. M. Shapley (1982) X and Y cells in the lateral geniculate nucleus of macaque monkcys. J. Physiol. (Lond.) 330:125144.

Kiorpes, L., R. G. Boothe, A. E. Hendrickson, J. A. Movshon, H. M. Eggers, and M. S. Gizzi (1987) Effects of early unilateral blur on the macaque's visual system. I. Behavioral observations. J. Neurosci. 7: $1318-1326$.

LeVay, S., T. N. Wiesel, and D. H. Hubel (1980) The development of ocular dominance columns in normal and visually deprived monkey. J. Comp. Neurol. 191: 1-51.

LeVay, S., M. Connolly, J. Houde, and D. C. VanEssen (1985) The complete pattern of ocular dominance stripes in the striate cortex and visual field of the macaque monkey. J. Neurosci. 5: 486-501.

Leventhal, A. G., R. W. Rodieck, and B. Dreher (1981) Retinal ganglion cell classes in old-world monkey; morphology and central projections. Sciencc 213: 1139-1142.

Levi, D. M., and R. S. Harwerth (1980) Contrast sensitivity in amblyopia due to stimulus deprivation. Br. J. Ophthalmol. 64: 15-20.

Lin, C-S., and J. H. Kaas (1980) Effects of monocular deprivation on geniculo-cortical pathway in the owl monkey, Aotus trivirgatus. Neurosci. Lett. 18: 267-273.

Livingstone, M., and D. H. Hubel (1984) Anatomy and physiology of a color system in the primate visual cortex. J. Neurosci. 4: 309356.

Lund, J. S. (1980) Intrinsic organization of the primate visual cortex, area 17, as seen in Golgi preparations. In The Organization of the Cerebral Cortex, Proceedings of a Neuroscience Research Program Colloquium, F. O. Schmitt, F. G. Worden, G. Adelman, and S. G. Dennis, eds., pp. 105-124, MIT Press, Cambridge, MA.

Malpeli, J. G., and F. H. Baker (1975) The representation of the visual field in the lateral geniculate nucleus of Macaca mulatta. J. Comp. Neurol. 161: 569-594

Maunsell, J. H. R., and D. C. Van Essen (1983) The connections of the middle temporal visual area (MT) and their relationship to a cortical hierarchy in the macaque monkey. J. Neurosci. 3: 2563-2586.

Movshon, J. A., H. M. Eggers, M. S. Gizzi, A. E. Hendrickson, L. Kiorpes, and R. G. Boothe (1987) Effects of early unilateral blur on the macaque's visual system. III. Physiological observations. J. Neurosci. 7: 1340-1351.

Newsome, W. T., M. S. Gizzi, and J. A. Movshon (1983) Spatial and temporal properties of neurons in macaque MT. Invest. Ophthalmol. Vis. Sci. (Suppl.) 24: 106

Packer, O., C. Curcio, and A. Hendrickson (1986) Topography of photoreccptors in the Macaca nemestrina rctina. Assoc. Res. Vis. Ophthalmol. Abstr. (Suppl.) 27: 330.

Perry, V. H., and A. Cowey (1981) The morphological correlates of
$\mathrm{X}$ - and Y-like retinal ganglion cells in the retina of monkeys. Exp. Brain Res. 43: 426-428.

Perry, V. H., and A. Cowey (1986) The ganglion cell and cone distributions in the monkey's retina: Implications for central magnification factors. Vision Res. 25: 1795-1810.

Perry, V. H., R. Oehler, and A. Cowey (1984) Retinal ganglion cells that project to the dorsal lateral geniculate nucleus in the macaque monkey. Neuroscience 12: 1101-1124.

Robson, J. G., and N. Graham (1981) Probability summation and regional variation in contrast sensitivity across the visual field. Vision Res. 21: 409-418.

Schiller, P.H., and J. G. Malpeli (1978) Functional specificity of lateral geniculate nucleus laminae of the rhesus monkey. J. Neurophysiol. 41: 788-797.

Shapley, R., and V. H. Perry (1986) Cat and monkey retinal ganglion cells and their visual functional roles. Trends Neurosci. 9: 229-235.

Sherman, S. M., and J. Stone (1973) Physiological normality of the retina in visually deprived cats. Brain Res. $60: 224-230$.

Swindale, N. V., F. Vital-Durand, and C. Blakemore (1981) Recovery from monocular deprivation in the monkey. III. Reversal of anatomical effects in the visual cortex. Proc. R. Soc. London [Biol.] 219. 435-450.

Thibos, L. N., and W. R. Levick (1982) Astigmatic visual deprivation in cat: Behavioral, optical and physiological consequences. Vision Res. 22: 43-53.

Tieman, S. B. (1984) Effects of monocular deprivation on geniculocortical synapses in the cat. J. Comp. Neurol. 222: 166-176.

Tigges, M., A. E. Hendrickson, and J. Tigges (1984) Anatomical consequences of long-term monocular eyelid closure on lateral geniculate nucleus and striate cortex in squirrel monkey. J. Comp. Neurol. 227: $1-13$.

Tootell, R. B. H., and M. S. Silverman (1981) A comparison of cytochrome oxidase and deoxyglucose activity patterns in macaque visual cortex. Soc. Neurosci. Abstr. 7: 356.

Van Essen, D. C., W. T. Newsome, and J. H. R. Maunsell (1984) The visual field representation in striate cortex of the macaque monkey: Asymmetries, anisotropies, and individual variability. Vision Res. 24: $429-448$.

Vital-Durand, F., L. J. Garey, and C. Blakemore (1978) Monocular and binocular deprivation in the monkey: Morphological effects and reversibility. Brain Res. 158: 45-64.

von Noordcn, G. K. (1973) Experimental amblyopia in monkeys. Further behavioral observations and clinical correlations. Invest. Ophthalmol. 12: 721-726.

von Noorden, G. K., and M. L. J. Crawford (1977) Form deprivation without light deprivation produces the visual deprivation syndrome in Macaca mulatta. Brain Res. 129: 37-44.

von Noorden, G. K. and P. R. Middleditch (1975a) Histological observations in the normal monkey lateral geniculate nucleus. Invest. Ophthalmol. 14: 55-58.

von Noorden, G. K. and P. R. Middleditch (1975b) Histology of the monkey lateral geniculate nucleus after unilateral lid closure and experimental strabismus: Further observations. Invest. Ophthalmol. 14: 674-683.

von Noorden, G. K., J. E. Dowling, and D. C. Ferguson (1970) Experimental amblyopia in monkeys. I. Behavioral studies of stimulus deprivation amblyopia. Arch. Ophthalmol. 84: 206-212.

von Noorden, G. K., M. L. J. Crawford, and P. R. Middleditch (1977) Effect of lid suture on retinal ganglion cells in Macaca mulatta. Brain Res. 122: 437-444.

von Noorden, G. K., M. L. J. Crawford, and R. A. Levacy (1983) The lateral geniculate nucleus in human anisometropic amblyopia. Invest. Ophthalmol. Vis. Sci. 24: 788-790.

Wilson, J. R., and A. E. Hendrickson (1981) Neuronal and synaptic structure of the dorsal lateral geniculate nucleus in normal and monocularly deprived Macaca monkeys. J. Comp. Neurol. 197: 517-539.

Wong-Riley, M. T. T. (1979) Changes in the visual system of monocularly sutured or enucleated cats demonstrable with cytochrome oxidase histochemistry. Brain Res. 171: 11-28.

Wong-Rilcy, M. T. T., and E. W. Carroll (1984) Effect of impulse blockage on cytochrome oxidase activity in monkey visual system. Nature 307: 262-263. 